\title{
Ensaio de uma (auto)crítica: o direito civil contemporâneo entre a tábua axiológica constitucional e a constituição prospectiva
}

\author{
Sketching a (self-)critique: contemporary civil law between the "axiological \\ constitutional tablet" and the prospective constitution
}

André Luiz Arnt Ramos*

\section{Resumo}

O pertencimento e a submissão do Direito Civil Brasileiro à ordem constitucional são voz corrente na teoria e na prática jurídicas contemporâneas. Isto se deve à contribuição de estudiosos que cunharam expressões-chave necessárias à assimilação da travessia que conduz à afirmação Estado Constitucional. Dentre elas, destaca-se a "tábua axiológica constitucional", há muito insculpida na produção técnica da civilística brasileira. A transposição das resistências iniciais ao fenômeno da constitucionalização, mormente pela crescente complexidade que a ele se agregou, contudo, põe em questão a força daquele sintagma. É que "tábua" remete a rigidez, o que contrasta com a fluidez e a dinamicidade inerentes à tríplice constituição do Direito Civil. Nesta ordem de ideias, noções novidadeiras em matéria Civil-Constitucional podem se ver reféns da linguagem empregada no âmbito teórico e prático do Direito. À vista disso, propõe-se uma (auto)crítica quanto à pertinência da consagrada expressão "tábua axiológica" no Direito Civil Contemporâneo.

Palavas-chave: Tábua axiológica. Direito civil contemporâneo. Constitucionalização do direito civil.

\section{Abstract}

\begin{abstract}
Constitutionalization of Private Law is subject of a widespread consensus among Brazilian legal scholars and practitioners. It is so partly due to the contribution of academics who created key-expressions that became indispensable to understanding the emergence of Verfassungsstaat. Among such expressions, the "constitutional axiological tablet" is particularly distinct and has long been incorporated to current legal discourse. After overcoming the inertia concerning constitutionalization and in the light of an ever-growing complexity attached to it, the aforementioned syntagma must be called into question. The word "tablet" refers to stiffness, which contrasts with the dynamic and fluid character of the so-called triple constitution of Civil Law. In this context, even new subjects dear to Civil-Constitutional ideals might be held hostage by language spoken by scholars and practitioners. With that in mind, this article traces a (self-)critique of allusions tothe "axiological tablet" in contemporary Civil Law.
\end{abstract}

Keywords: Axiological tablet. Contemporary civil law. Constitutionalization of private law.

\section{Introdução}

Os caminhos e descaminhos da constitucionalização do Direito são há muito conhecidos pela comunidade jurídica, ${ }^{1}$ inclusive, e particularmente, pela brasileira. ${ }^{2}$ Sem embargo de alguma resistência inicial e de críticas ainda pungentes, ${ }^{3}$ é seguro falar na progressiva instauração de um modelo de Estado

Doutorando e Mestre em Direito das Relações Sociais e Bacharel em Direito pela UFPR. Visting researcher junto ao Instituto Max Planck para Direito Comparado e Internacional privado. Membro do Grupo de Pesquisa Virada de Copérnico - Eixo de Titularidades. Associado ao Instituto dos Advogados do Paraná. Professor da Universidade Positivo. Advogado em Curitiba. Curitiba-PR-Brasil. E-mail: a.arntramos@gmail.com.

Cf., por todos, Barkhuysen e Lindenbergh (2006).

V., para uma síntese abrangente: Schreiber (2013).

Por exemplo: "na atualidade, o fenômeno constitucional brasileiro gira pela ação de três forças, felizmente bem distintas daquelas antigas: o sentimento constituinte, o constitucionalismo chapa branca e o compromisso com a governabilidade. Sustento que a Carta de 1988, para os homens do Direito, tem valido mais pela aura que por seus preceitos, que ela é uma Constituição chapa branca, não uma romântica Constituição-cidadã, e, ainda, que ela tem um potencial desestabilizador cuja superação tem dependido do compromisso com a governabilidade do meio político e dos Tribunais" (SUNDFELD, 2012, p. 49). 
Constitucional ${ }^{4}$ em solo brasileiro, tal qual operado, também em meio a sístoles e diástoles, em contextos bastante diversos. ${ }^{5}$

Alcançou-se certo consenso estabilizador em torno da submissão dos diversos ramos do Direito às normativas constitucionais - sobretudo em sua principiologia axiológica - graças à contribuição incansável de diversos estudiosos, os quais, radicados em grupos prestigiadores do constitucionalismo democrático, consagraram ideias e ideais com ele consentâneos nos corações e mentes dos integrantes de uma renovada comunidade especializada. ${ }^{6}$

Em meio aos esforços que permitiram a inserção da temática constitucionalização do Direito Civil na ordem do dia, está a cunhagem de expressões-chave, que trazem consigo um conjunto de sentidos fortemente imantado pelo desiderato de entender o Direito e, em cumprimento aos ditames constitucionais (e convencionais), transformar a realidade. Dentre essas expressões, destaca-se, por sua incrível recorrência na literatura jurídica, o da "tábua axiológica constitucional". Inaugurada, no contexto brasileiro, por Tepedino, em aula inaugural no ano acadêmico de 1992, proferida no Salão Nobre da UERJ.7

Dado o seu inegável caráter didático, as referências, na doutrina brasileira, à expressão tábua axiológica são recorrentes e bem qualificadas. Assim, por exemplo, Oliva e Rentería afirmam que "com a promulgação da Constituição da República de 1988, o direito civil encontra-se renovado e funcionalizado à tábua axiológica nela consagrada, que informa todos os institutos de direito privado".

Muito embora tenha contribuído sobremaneira para a delimitação daquilo que hoje se conhece como metodologia Civil-Constitucional, a dita expressão talvez integre, hoje, a contramarcha da exploração das potencialidades dessa abordagem. As razões pelas quais isto se verifica são objeto da presente análise, a qual visa a pontuar aspectos contemporâneos das Teorias da Constituição e do Direito Civil, para então pôr a prova o viés vanguardista do sintagma tábua axiológica na contemporaneidade, sempre ressalvando sua distinta importância para o florescimento do Direito Civil Contemporâneo.

\section{0 direito civil-constitucional: por que precisávamos de uma tábua axiológica?}

O termo inicial da assimilação da ideia de um Direito Civil-Constitucional pela literatura jurídica brasileira remonta à produção acadêmica havida no alvorecer da Constituição Federal de 1988. É que, apesar das críticas dirigidas à prodigalidade do então novo texto e à inexistência de uma diretriz uniformizadora bem definida, os compromissos constitucionais em torno da promoção da dignidade humana e da solidariedade social, agregados à celebração de um extenso rol de direitos e garantias fundamentais, viabilizou uma profunda reconsideração dos institutos fundamentais de Direito Civil (OLIVA; RENTERÍA, 2015, p. 104).

A absorção, pelo texto constitucional, de uma série de conteúdos não patrimoniais, interfere diretamente nos tradicionais institutos do Direito Privado. ${ }^{8}$ Mais que isso: impulsionou um repensar da idolatria do Código

\footnotetext{
"Modelo constitucional", conquanto não corresponda, exatamente, a uma expressão valorativa, comporta pontual esclarecimento: "Por 'modelo constitucional' queremos dizer o conjunto de crenças médias, dos intérpretes, da classe política e dos cidadãos, a determinar a vida concreta da Constituição, dando-Ihe significado" (FIORAVANTI, 2001) Tradução livre. No original: "Per 'modello costituzionale' intendiamo quel l'insieme di convinzioni medie, degli interpreti, della classe politica, degli stessi cittadini, che determinano la vita concreta della Costituzione, attribuendole un significato prevalente".

Cf. Bodin de Moraes (2012, p .1-5) e Fioravanti (2013, p. 21).

6 A valia de uma perspectiva crítica vis-à-vis a abordagem tradicional é assim enaltecida por Fachin (2012, p. 99): "Essa eleição de caminho pelo viés tradicional tem importância, posto que transmite ordem de conceitos destinada a solver, de antemão, os problemas fundamentais, e, desse modo, propõe a criar corações e mentes aptos a compreender o Direito Civil. Porém, essa via pode ser falaciosa. De um lado, porque aprisiona a realidade aos conceitos; de outro, porque reduz o Direito Civil às questões de esgrima positivista, de habilidade no decifrar de axiomas e na escola do que está, previamente, eleito".

O conteúdo dessa célebre introdução veio a ser publicado em Tepedino (1999).

Neste particular, duas referências tácitas a Perlingieri (2002, p. 60) merecem pontuação: (i) a noção de dogmatismo, que é por ele assim endereçada: "A reflexão sobre conceitos é usualmente definida na ciência jurídica como 'dogmática'. [...] Passa-se da dogmática ao dogmatismo quando a análise conceitual degenera no gosto pela classificação finalizada a si mesma, esquecendo a sua função e alienando-se da realidade"; e (ii) a chamada despatrimonialização, acerca da qual afirma: "Nessa ótica, que tende à redefinição e à ampliação da lógica privatística, inserta cada vez mais na unidade e complexidade do ordenamento, devem deslocar-se os esforços da civilística. [...] A 'despatrimonialização' do direito civil é o caminho para a reconstrução do sistema. Não é uma moda, mas uma escolha de política legislativa de alcance histórico”. (PERLINGIERI, 2002, p. 65-66).
} 
Civil como a constituição do indivíduo ${ }^{9}$ e continente exclusivo das soluções para problemas inerentes às relações interprivadas - malgrado os recortes historicamente promovidos, em prestígio não à pessoa, mas a quatro avatares do sujeito de direito: contratante, marido, proprietário e testador. ${ }^{10} \mathrm{~A}$ celebração de compromissos substantivos em torno do extenso rol de direitos e deveres fundamentais mina a acepção moderna de Constituição como Carta Política. Anima, pois, uma nova percepção sobre o sentido e a função da Constituição. Nesta senda, opera, na fratura da summa divisio, uma tendencial despatrimonialização do Direito Civil, mediante tutela prioritária ao ser humano, cuja dignidade serve de norte para todo o Direito (BODIN DE MORAES, 1993, p. 26). Assim, é que: "a mudança paradigmática, portanto, não é tanto daquele a quem se atribui direitos (sujeito ou pessoa), mas sim a razão (ratio) pela qual esses direitos lhes são atribuídos" (SCHREIBER; NEVARES, 2016, p. 40).

Um redimensionamento assim amplo da disciplina jurídica das relações interprivadas é tributário de uma ordem de acontecimentos prévia à promulgação de texto constitucional afinado a democracias pós-Segunda Guerra. Vale dizer: a unidade do Código se implodiu - ocasionando uma fragmentação da ordem jurídica - e deu vez a uma espécie de sistema planetário, em que corpos estatutários esparsos regulam, cada um a seu modo, aspectos da vida em relação (LORENZETTI, 1998, p. 45). Sem embargo da preservação da Parte Geral codificada, então, o sistema-código viu fraturados seus ângulos e parâmetros. Daí se falar no sacrifício, em nome da especialidade, da sistematicidade, que funda a noção de segurança (formal), cara ao ideário codificador.

A proliferação, nesta esteira, de regimes especiais não unificados segundo os parâmetros da codificação, somada à acepção de separação de poderes, cara ao modelo de Estado de Direito, ampliou um problema de relação entre caso e sistema. A propósito, diz Lorenzetti (1998, p. 80):

A crise do Código desencadeia um problema de relação entre caso e sistema; há um retorno ao casuísmo e uma reconsideração do sistema. [...] O casuísta entende que o Direito, ainda que apoiado em normas, só se realiza na decisão dos casos, de modo que a solução repousa na percepção do problema concreto. [...] O pensamento sistemático, diferentemente, concebe o Direito como um conjunto estruturado de normas jurídicas, racionalmente elaborado que além de uma ordem interna tem uma conexão conceitual interna e encerra em si mesmo todas as soluções possíveis para os problemas que se apresentam na vida social.

É nesse contexto - embora com propulsão concorrente advinda da derrocada de regime antidemocrático - que advém a Constituição de 1988, marco de inauguração formal do Estado Constitucional no Brasil. ${ }^{11}$ Com ela, o já combalido valor performático do Código veio à ruína. Mas isto não significa a ocorrência de uma transição completa para um novo estado de coisas. Antes, segundo o ideário dominante à época, era necessário reunificar o Direito Privado. ${ }^{12}$ Nesse propósito restaurador de um encéfalo ao governo jurídico das relações interprivadas, a regência constitucional de temas a si caros dava um novo e sonoro tom. Um tom que esfacelava os valores da igualdade formal, caros aos contratantes, maridos, proprietários e testadores,

9 "O Direito Civil, ao longo de sua história no mundo romano-germânico, sempre foi identificado como o lócus normativo privilegiado do indivíduo enquanto tal. A partir do constitucionalismo moderno, nenhum ramo do direito era mais distante do direito constitucional do que ele. Em contraposição à constituição política, era cogitado como constituição do homem comum" (LÔBO, 2013, p. 35). No mesmo sentido, após elencar, ilustrativamente, as matérias disciplinadas pelo Código Civil, diz Bydlinski (1994, p. 321): "O Direito Privado é um ramo do Direito que regula as atividades normais das pessoas entre si, não qualificadas por especiais funções estatais" (tradução livre. No original: "Das Privatrecht ist jenes Recht, das sich an die 'normalen', nicht durch Staatsfunktionen qualifizierten Personen für ihre Beziehungen untereinander richtet").

10 Este recorte, bastante enfatizado por Tepedino (2016, p. 2) e por Fachin (2012, p. 98), corresponde ao que Lorenzetti (1998, p. 87) alcunha de umbrais do Direito Privado. Diz ele: "Existe um umbral de entrada ao Direito Privado, que importa a exclusão de grandes grupos de pessoas: nem todos chegam a ser proprietários, contratantes, trabalhadores ou autores em um processo. Estas exclusões permaneciam ocultas sob nossos esquemas mentais: é a forma como se vê que impede a visão. Trata-se de condicionamentos epistemológicos que impedem apreciar o que é evidente, e quando mudam, outras evidências surgem".

11 Malgrado as virtudes da consolidação de uma ordem declaradamente democrática, há, de fato, um "'mal-estar constitucional' (ao qual a literatura jurídica constitucionalista denomina de frustração do sentimento constitucional causada principalmente pela insinceridade normativa), já que o Estado Democrático de Direito não se efetivou em termos substanciais no plano sócio-econômico" (FACHIN, 2014, p. 13).

12 Diz Tepedino (2013, p. 3): "Assim como na Europa Continental, numerosas leis especiais passaram a regular setores relevantes do ordenamento, na medida em que a disciplina do Código era considerada mais e mais ultrapassada. Este processo, amplamente registrado em doutrina, conhecido como movimento de descodificação, na experiência brasileira reservou à Constituição de 1988 o papel reunificador do sistema". 
em prol da afirmação da igualdade substancial dos valores da pessoa histórica e concretamente situada. É o que confirma o parecer de Fachin e Pianovski Ruzyk (2003, p. 99):

\begin{abstract}
A Constituição deixa de ser reputada simplesmente uma carta política, para assumir uma feição de elemento integrador de todo o ordenamento jurídico [...]. Perde sentido o binário interioridadeexterioridade dos direitos fundamentais, que adquirem, também, feição prestacional [...]. Os três pilares de base do Direito Privado - propriedade, família e contrato - recebem nova leitura, que altera suas configurações, redirecionando-os de uma perspectiva fulcrada no patrimônio e na abstração para outra racionalidade que se baseia no valor da dignidade da pessoa. De fato, modelos e conceitos não são o verdadeiro objeto do direito, mas, apenas, seu instrumento.
\end{abstract}

Daí se fazia necessária uma ideia que, sem degenerar o texto constitucional para um macrocódigo, trouxesse consigo a rigidez e a segurança prestigiadas pela comunidade jurídica ressentida pelo alardeado fim de uma era. ${ }^{13}$ Esses atributos foram sagazmente vislumbrados em expressão que remete ao decálogo fundamental da cristandade e às tábuas da lei romanas, e que ostentava o condão de firmar o solo do porvir que já se materializava: a tábua de valores da constituição. Assim:

Diante do novo texto constitucional, forçoso parece ser para o intérprete redesenhar o tecido do direito civil à luz da nova Constituição. De modo que, reconhecendo embora a existência dos mencionados universos legislativos setoriais, é de se buscar a unidade do sistema, deslocando para a tábua axiológica da Constituição da República o ponto de referência antes localizado no Código Civil (TEPEDINO, 1999, p. 13).

A tábua axiológica, vale dizer, refunda o ordenamento e lhe restitui um marco estabilizador, mas sua rigidez não sobreviveria às mudanças no estado da arte - compreensivas tanto dos influxos e refluxos da teoria e da prática do Direito como também das sucessivas transformações da ordem constitucional vigente, com ou sem alteração de texto. Nessa ordem de ideias, fortemente timbrada por uma dimensão prospectiva da constituição (não só) do Direito Civil, e pela consequente noção de mutação constitucional (Verfassungsverwandlung), a dimensão formal da constitucionalização do Direito, mesmo que conjugada a sua correspondente substancial, dá sinais de insuficiência. A assimilação daquela - de rigor, há muito presente - eleva-se, pois, à ordem do dia.

\title{
3 O direito civil contemporâneo e sua tríplice constituição: por que reconsiderar a expressão "tábua axiológica"?
}

O Direito Civil Contemporâneo, muito em virtude da plêiade de sentidos irradiados por expressões-chave contidas nas obras fundamentais da temática Civil-Constitucional brasileira, é cioso de seu pertencimento e de sua subserviência à Ordem Constitucional, daí o porquê de a ênfase na autonomia do sujeito in abstracto ter migrado para a promoção dos interesses da pessoa in concreto, sempre sob regência da principiologia axiológica constitucional. A emergência de um "novo sujeito, alguém que tenha uma existência concreta, com certos direitos constitucionalmente garantidos: vida, patrimônio mínimo [...] e sobrevivência" (FACHIN, 2012, p. 207), sinaliza a crise do Direito Civil tradicional e o alvorecer de um Direito que não é "somente isso que está aí" (FACHIN, 1998, p. 319). Vale dizer: informado por uma nova ordem fundante, o governo jurídico das relações interprivadas muda de figura. Neste diapasão:

é preciso avaliar a mudança do ponto de vista sistemático, ressaltando que se a normativa constitucional está no ápice de um ordenamento jurídico, os princípios nela presentes se tornam, em consequência, as normas diretivas, ou normas-princípios, para a reconstrução do Direito Privado. [...].

13 Trata-se da Era da Codificação, que, à época, pensava-se decadente diante da antitética Era da Descodificação. "Diante da nova Constituição e da proliferação dos chamados microssistemas, como, por exemplo, a Lei do Direito Autoral, e recentemente, o Estatuto da Criança e do Adolescente, o Código de Defesa do Consumidor e a Lei das Locações, é forçoso reconhecer que o Código Civil não mais se encontra no centro das relações de direito privado. Tal pólo foi deslocado, a partir da consciência da unidade do sistema e do respeito à hierarquia das fontes normativas, para a Constituição, base única dos princípios fundamentais do ordenamento" (BODIN DE MORAES, 1993, p. 24). 
Nos Estados democráticos, [...] a primazia da ordem jurídica consubstancia-se na primazia das decisões políticas em face da natureza das coisas, devendo o legislador não só se esforçar por refletir a realidade, mas também, conscientemente, buscar a sua transformação. O Direito é justamente isto, uma força de transformação da realidade (BODIN DE MORAES, 2003, p. 107-108).

A promulgação da Constituição de 1988, então, foi além de representar o advento de um renovado Direito Constitucional Positivo (a integrar a constituição formal do Direito Civil). Inaugurou toda uma ordem de princípios (conformadora da constituição substancial) e franqueou espaço à atividade hermenêutica centrada na atribuição de sentido aos significantes que integram o governo jurídico das relações interprivadas, à vista não só das normativas constitucionais e infraconstitucionais, mas também da força confessadamente jurígena dos fatos (constituição prospectiva). ${ }^{14}$

Eis, então, o momento decisivo da frutificação de uma "teoria que não se deixa enclausurar, não se pautando em conceitos prontos; que não se pretende estática, reconhecendo a transitoriedade; que recolhe a juridicidade emergente da facticidade sem negar a normatividade das leis e da Constituição" (RUZYK, 2012, p. III). Esta revigorada postura hermenêutica, de matriz, a um só tempo, tópica e sistemática, ${ }^{15}$ põe-se em diálogo com a dinamicidade (e, portanto, com a essencial mutabilidade) inerente ao fenômeno constitucional, a qual ostenta importância decisiva na percepção do estado da arte.

Uma orientação assim desenhada não rende homenagens à chamada vulgarização ${ }^{16}$ ou carnavalização ${ }^{17}$ do Direito, ou ainda ao protraído sentimento constituinte criticado pela literatura cética. ${ }^{18}$ Antes, quer enaltecer a virtude da conjugação - se bem que aporética - da tendência antissistemática e antilogicista da tópica ${ }^{19}$ ao rigor do pensamento sistemático, isto é, o encaixe do pensamento problemático nos horizontes de um sistema, que não pode ser senão poroso, aberto e plural. ${ }^{20}$ Assim, na didática explanação de Pianovski Ruzyk (2013, p. 152-153):

A incompletude é traço inafastável de um saber que se pretende crítico, e que, nessa medida, não se compraz com construções dogmáticas que aspirem à estabilidade e a assunção de um lugar de verdades definitivas. A construção do saber se dá pela problematização e pela provisoriedade das conclusões, ainda que dotadas de pretensão de veracidade. [...] Rechaçar as pretensões de clausura e de completude importa ponderar sobre a importância de se pensar o saber pertinente à Teoria do Direito Civil como um sistema. [...] não [...] mais como nos termos da Teoria Geral do Direito Civil de

14 A respeito da tríplice constituição do Direito Civil, ver: Fachin (2015).

15 Oportuna a explanação de Fachin (2015, p. 7): "a tópica corresponde a um procedimento racional que se dirige a refletir por problemas a partir da abertura semântica de alguns significantes ou signos linguísticos (é o que chamamos de investigação das possibilidades dentro dos limites internos do sistema), e sua junção com o pensamento sistemático se dá, aqui, precisamente porque se opera com plúrima noção de sistema, haurido então, em vários significados, ora como conjunto de conceitos, ora como a composição de sentidos verificados pela função, mas sempre aberto, poroso e plural, de tal modo que se apresenta aqui o limite externo, o da unidade do sistema".

16 Esse fenômeno nos remete à "entrega ao Direito emotivamente criado pelos juízes, sem controle de legalidade e justificado em menores argumentos de conveniente equidade, quando não de propaganda" (PERERA, 1988, p. 86). Tradução livre. No original: "entrega al Derecho emotivamente creado por los jueces, sin controle de legalidade y justificado em menores argumentos de conveniente equidade, cuando no de propaganda".

17 É a alcunha utilizada por Konder (2015, p. 205), na seguinte passagem: "De fato, o cenário aterrador com que nos confronta a jurisprudência contemporânea é de decisões que, às vezes até mesmo sob o pretexto da abertura do sistema pela constitucionalização e da aplicação dos princípios, mais parecem realizar o que vem sendo chamado de banalização ou mesmo 'carnavalização' do Direito".

18 Está-se a referir a Sundfeld (2012, p. 54), que registra: "O sentimento constituinte é, em suma, uma atitude de soberba, construída na base do desprezo aos políticos ('impuros'), que autoriza os homens do Direito ('os puros') a elaborar, no interior de seu próprio mundo (as Academias e os Tribunais), soluções jurídicas para problemas administrativos, econômicos, sociais e de organização política, com relativa autonomia frente à ordem legal editada pelo Poder Legislativo. É uma força maior do fenômeno constitucional brasileiro, que levou nossa literatura e nossa jurisprudência a terem um caráter muito mais constitutivo, originário, criativo, do que seria de se esperar ante uma Carta tão analítica".

19 "[A] relação da tópica e da argumentação em sua orientação antissistemática e antilogicista se radica em considerar que o raciocínio jurídico não é e nem deve ser sistemático, ou seja, deduzível a partir de sistemas fechados, mas tópico - a partir de problemas ou casos abertos" (CALFURRAPA, 2012, p. 585). Tradução livre. No original: "la relación de la tópica y la argumentación en su orientación antisistemática y antilogicista radica en considerar que el razonamiento jurídico no es ni debe ser sistemático, es decir, deducible a partir de sistemas cerrados, sino tópico - a partir de problemas o casos abiertos".

20 Os sistemas abertos, malgrado assimilados pelas Humanidades (cf. LASZLO, 1990) remetem às ciências duras, nas quais se explicam como "sistemas que participam em algum tipo de intercâmbio contínuo com o ambiente. Caracterizam-se, estes sistemas, por certa dose de flutuação, isto é, são vulneráveis e acessíveis a diferentes tipos de energia, matéria e informação que penetram neles e que fluem através de suas estruturas" (GRÜN, 1998, p. 168, tradução livre). No original: "sistemas que participan en algún tipo de intercambio continuo con el ambiente. Se caracterizan estos sistemas por una cierta dosis de fluctuación, es decir, son vulnerables y accesibles a diferentes tipos de energía, materia e información que penetran en ellos y que fluyen a través de sus estructuras"). Na literatura jurídica, olhares atentos percebem que: "sucumbe a completude como dogma que a teoria tradicional do Direito Civil, em constante visão de excludência social (por vezes direta, em outras indireta), pela compreensão do sistema como aberto, visto não se exaurir em regras, incompleto porém sempre completável sob pena de anomia - por inexistir lacuna de valores - que conduz a necessidade de resposta e proximidade social do Direito para com o destinatário da ordem jurídica" (ARONNE, 2006, p. 46). 
base Pandectista, como sistema completo e fechado em seus próprios conceitos [...], mas, sim, como sistema dotado de abertura [...]. A abertura da Teoria do Direito Civil impõe a intersecção com outros ramos do Direito e a porosidade aos fenômenos concretos objetos de normatização; a abertura do sistema jurídico, a seu turno, impõe a abertura do Direito à força normativa que emerge dos fatos, como resultado das demandas sociais.

Tudo isso se imbrica no contexto da interseção entre as viragens caras à emergência do Estado Constitucional e os contemporâneos debates havidos na Teoria do Direito, mormente no âmbito da teoria da interpretação, que rechaça o combalido (mas ainda latente na prática jurídica brasileira) mito da unidade entre texto e norma, ${ }^{21}$ afirmando, peremptoriamente, a existência de uma dualidade. ${ }^{22}$

Nessa ordem de ideias, e a exemplo da ruina da ideia de sistema fechado em Direito (Civil) diante do enaltecimento de sua constituição prospectiva, insere-se a temática das mutações constitucionais. Em outras palavras, das alterações informais das normas da Constituição, em detrimento dos textos correspondentes, mas sem sacrifício de sua supremacia e de sua força normativa. ${ }^{23}$

As mutações constitucionais, assim, são "uma constante na vida dos Estados e ocorre[m] porque o significado da Constituição não é dado de antemão, mas depende do contexto no qual é concretizado" (PEDRA, 2010, p. 10). Exprimem um fenômeno empiricamente verificável, haurido de inputs e outputs de corpos normativos com a realidade cotidiana, e sujeito, em nome da controlabilidade que vivifica a segurança jurídica, a determinados limites vincados na sistematicidade do ordenamento jurídico.

A dimensão prospectiva, umbilicalmente vinculada às suas correspondentes formal e substancial, portanto, é constitutiva da Constituição para além do Direito Civil. Esta constatação, cuja consistência imprescinde a aderência à postura hermenêutica tópica e sistemática, põe a desnudo o descompasso da rigidez inata à noção de tábua axiológica com a ordem do dia. É que, se a Constituição se sujeita, ela mesma, a alterações informais (sem observância da rigidez do procedimento para exercício do poder constituinte derivado), não pode encerrar uma tábua de valores. ${ }^{24}$ Ademais isso, e desde o prisma hermenêutico, cujo desenvolvimento escapa às pretensões deste texto, há o dificultoso problema da incontrolabilidade dos valores, ${ }^{25}$ muito embora esse sintagma tenha sido decisivo para a afirmação, na ágora dos civilistas, da supremacia e da força normativa da Constituição.

Não se está, entretanto, a reprochar ou militar pela peremptória condenação da expressão. Há, para bem, escritos exemplares que a empregam, sem recair em anacronismos ou dela extrair sentidos inadequados para com o estatuto do Direito Civil Contemporâneo. Um exemplo eloquente é a seguinte passagem de Tepedino (2016, p. 20-22):

A reconstrução dogmática genuinamente civilista há de se operar a partir de valores e princípios constitucionais na perspectiva do sistema aberto. [...].

21 A advertência de Zaneti Junior (2014, p. 179-180) é emblemática neste ponto: "A teoria da interpretação é central para a correta compreensão da dogmática jurídica contemporânea. O direito lida com textos. Os textos precisam ser interpretados. Não se podem mais confundir, como se fazia uma vez, texto e norma, o dispositivo e seu sentido normativo. A clareza do texto pode contribuir para a sua interpretação, mas não a elimina. As normas não se confundem com os textos e o que se aplica no direito são as normas, não os textos".

22 Daí se dizer, e.g., que: "os textos legais (ou enunciados normativos) 'constituem uma mera possibilidade de Direito', pois sua transformação em normas jurídicas 'depende da construção de conteúdos de sentido pelo próprio intérprete' [...]. Normas não são, portanto, a matéria bruta do raciocínio jurídico, pois sua formulação depende da inteligência de um (ou mais de um) determinado enunciado estabelecido pelo legislador, por meio de um processo mental de interpretação ou adscrição de sentido" (BUSTAMANTE, 2012, p. 233).

23 "A mutação constitucional está vinculada à existência de uma Constituição dotada de força normativa. A Constituição deve ser tanto normativa quanto dinâmica. Enquanto a força normativa da Constituição será responsável pela conformação da vida em sociedade, o caso concreto conferirá dinamicidade às normas constitucionais" (PEDRA, 2010, p. 13).

24 Poder-se-ia objetar ao argumento de que os princípios fundamentais da República e os direitos e garantias individuais figuram entre as cláusulas pétreas, que estão imunes à ação erosiva dos poderes constituídos. Se fosse o caso, caberia menção ao ocorrido com a Constituição Portuguesa: sua redação originária, de 1976, previa a nacionalização e socialização dos meios de produção (art. $82^{\circ}$ ) e instituía, como cláusulas pétreas (limites materiais da revisão constitucional), "o princípio da apropriação colectiva dos principais meios de produção e solos, bem como dos recursos naturais, e a eliminação dos monopólios e dos latifúndios" e "a planificação democrática da economia" (art. $290^{\circ}$, f e g). No curso de revisões constitucionais, o caráter pétreo dessas cláusulas foi debelado, de modo que se pôde alterar a redação do art. $82^{\circ}$ para asseguração de três setores de propriedade dos meios de produção: público, privado e cooperativo, no contexto de uma economia declaradamente mista - sendo, este caráter mestiço, elevado ao patamar de cláusula pétrea pelo atual art. $288^{\circ}, \mathbf{f}$ e $\mathbf{g}$, da CRP. Um exemplo concreto e prospectivo, respeitante ao debate acerca do chamado direito ao esquecimento no contexto brasileiro, será abordado adiante.

25 A propósito: "defende-se, ao mesmo tempo, um direito constitucional da efetividade; um direito assombrado pela ponderação de valores; uma concretização ad hoc da Constituição e uma pretensa constitucionalização do ordenamento [...]. Tudo porque, ao fim e ao cabo, acreditou-se ser a jurisdição responsável pela incorporação dos 'verdadeiros valores' que definem o direito justo” (STRECK, 2013, p. 187-188). 
Nesta direção, atribui-se cada vez mais aos princípios o papel de reunificação do Direito Civil a partir da releitura de tradicionais institutos à luz da tábua axiológica constitucional, atribuindo-se ao magistrado a missão de delimitar categorias e conceitos jurídicos indeterminados, de modo a assegurar eficácia jurídica às cláusulas gerais positivadas pelo legislador. [...] O modelo teórico, racional e abstrato, desvinculado da práxis, cede lugar ao pensamento tópico-sistemático, atento à realidade social. [...]. A complexidade do ordenamento, em última análise, não decorre apenas de sua gênese [...] mas da tensão dialética representada por sua inserção na realidade social. A experiência vivida forja a norma, e a cultura [...] condiciona internamente o sistema jurídico e, conseguintemente, a teoria da interpretação, que assume necessariamente feição procedimental.

A crítica, neste passo, não se dirige àqueles que, fieis à expressão há muito consagrada, empregam-na ao tempo em que ingressam, mesmo sem dizer expressamente, nos meandros da constituição prospectiva do Direito Civil na contemporaneidade. Antes, tem por objeto a distorção que seu emprego descontextualizado gera na percepção cotidiana de uma comunidade jurídica vitimada por um ensino decadente, inexplicavelmente amarrada a acepções ultrapassadas quanto a noções elementares para compreender o atual estado da arte. Visa a alertar para o risco de que a tábua axiológica venha, paradoxalmente, a obstruir as possibilidades de desenvolvimento de soluções jurídicas orientadas para o futuro e consentâneas com a principiologia axiológica de índole constitucional, isto é, intenta elidir o risco, bastante presente, de que de tábua de salvação, a tábua axiológica, se converta em paletó de madeira do Direito Civil Contemporâneo.

\section{Conclusão}

Apesar da resistência inicial, alcançou-se certo consenso em torno da submissão dos diversos ramos do Direito às normativas constitucionais graças à contribuição incansável de diversos estudiosos. Essa estabilidade foi possível, em grande parte, ao emprego de expressões didáticas, de fácil compreensão e apreensão, dentre as quais a da "tábua axiológica constitucional". Não obstante, após a superação da resistência inicial quanto à Constitucionalização do Direito (Civil), observa-se uma tendência de recrudescimento, a qual, em franco descompasso com o estado da arte, busca (oculta ou explicitamente) limitar o campo de interpretação e integração das normativas constitucionais, máxime daquelas que exprimem conteúdo marcadamente axiológico.

Os debates travados nos Tribunais Superiores brasileiros envolvendo o direito ao esquecimento são um exemplo. Não raras vezes, a ausência de enunciação expressa de determinado direito ou garantia é invocada como argumento para afastar ou limitar sua tutela, como se o Direito se resumisse à lei. Nesse contexto, a partir da percepção de que a remissão à tábua axiológica não é suficiente, pois pode aludir a um rol delimitado de direitos e garantias, buscam-se novas sintaxes para explicar a amplitude da dimensão prospectiva da Constituição.

Demonstrou-se, neste trabalho, que a alegada "ausência de demarcação do direito ao esquecimento no ordenamento jurídico" é argumento que não encontra respaldo na contemporânea realidade constitucional brasileira, isto porque a promulgação da Constituição de 1988 foi além de representar o advento de um renovado Direito Constitucional Positivo. Antes, franqueou espaço ao florescimento de atividade hermenêutica centrada na atribuição de sentido aos significantes que integram o governo jurídico das relações interprivadas, simultaneamente atenta às peculiaridades de cada problema em concreto e aos limites internos e externos da unidade do sistema.

\section{Referências}

ARONNE, R. sistema jurídico e unidade axiológica: os contornos metodológicos do direito civilconstitucional. In: ARONNE, R. Direito civil-constitucional e teoria do caos: estudos preliminares. Porto Alegre: Livraria do Advogado, 2006. p. 37- 62.

BARKHUYSEN, T.; LINDENBERGH, S. D. (Ed.). Constitutionalisation of private law. Leiden: Martinus Nijhoff, 2006. 
BODIN DE MORAES, M. C. A caminho de um direito civil constitucional. Revista de Direito Civil, São Paulo, ano 17, n. 65, p. 21- 32, jul./set. 1993.

BODIN DE MORAES, M. C. O conceito de dignidade humana: substrato axiológico e conteúdo normativo. In: SARLET, I. W. (Org.). Constituição, direitos fundamentais e direito privado. Porto Alegre: Livraria do Advogado, 2003. p. 107- 149.

BODIN DE MORAES, M. C. O jovem direito civil-constitucional (editorial). Civilística.com., Rio de Janeiro, ano 1, n. 1, p. 1- 4, jul.-set./2012.

BUSTAMANTE, T. R. Teoria do precedente judicial: a justificação e a aplicação de regras jurisprudenciais. São Paulo: Noeses, 2012.

BYDLINSKI, F. Kriterien und Sinn der Unterscheidung von Privatrecht und öffentlichem Recht. AcP, Göttingen, n. 194, p. 319-351, 1994.

CALFURRAPA, R. B. La tópica jurídica y su vinculación argumentativa con el precedente y la jurisprudencia. Revista de Derecho de La Pontifícia Universidad Católica de Valparaíso, Valparaíso, v. 39, n. 2, p. 587-606, 2012.

FACHIN, L. E. A tutela compromissária da Constituição na Corte Suprema. In: RUZYK, C. E. Pianovski et al. Direito civil constitucional: a ressignificação da função dos institutos fundamentais do Direito Civil Contemporâneo e suas consequências. Florianópolis: Conceito, 2014. p. 13-14.

FACHIN, L. E. Direito civil: sentidos, transformações e fim. Rio de Janeiro: Renovar, 2015.

FACHIN, L. E.; RUZYK, C. E. Pianovski. Direitos fundamentais, dignidade da pessoa humana e o novo Código Civil: uma análise crítica. In: SARLET, I. W. (Org.). Constituição, direitos fundamentais e direito privado. Porto Alegre: Livraria do Advogado, 2003. p. 87- 104.

FACHIN, L. E. Questões do direito civil contemporâneo. Rio de Janeiro: Renovar, 2008.

FACHIN, L. E. Teoria crítica do direito civil. 3. ed. revista e atualizada. Rio de Janeiro: Renovar, 2012.

FACHIN, L. E. "Virada de Copérnico": um convite à reflexão sobre o direito civil brasileiro contemporâneo. In: FACHIN, L. E. (Coord.). Repensando os fundamentos do direito civil contemporâneo. Rio de Janeiro: Renovar, 1998. p. 317- 324.

FIORAVANTI, M. La trasformazione del modello costituzionale. Studi Storici, Roma: Carocci, ano 42, n. 4, p. 814, out./dez. 2001.

FIORAVANTI, M. Público e privado: os princípios fundamentais da Constituição democrática. Revista da Faculdade de Direito UFPR, Curitiba, n. 58, p. 7-24, 2013.

GRÜN, E. El derecho posmoderno: un sistema lejos del equilibrio. DOXA, Alicante, v. 21, n. 2, p. $167-177,1998$.

KONDER, C. N. Distinções hermenêuticas da constitucionalização do direito civil: o intérprete na doutrina de Pietro Perlingieri. Revista da Faculdade de Direito UFPR, Curitiba, v. 60, n. 1, p. 193-213, jan.-abr. 2015.

LASZLO, E. La gran bifurcación. Barcelona: Gedisa, 1990.

LIMA, C. R. P. de. Direito ao esquecimento e internet: o fundamento legal no direito comunitário europeu, no direito italiano e no direito brasileiro. Revista dos Tribunais, São Paulo, v. 946, p. 77-109, ago. 2014.

LÔBO, P. L. N. Direito civil-constitucional. In: TEIXEIRA, A. C. B.; RIBEIRO, G. P. L. (Coord.). Manual de teoria geral do direito civil. Belo Horizonte: Del Rey, 2013. p. 35- 58.

LORENZETTI, R. L. Fundamentos do direito privado. Tradução de Vera Maria Jacob de Fradera. São Paulo: RT, 1998.

MARINONI, L. G. A ética dos precedentes. São Paulo: Revista dos Tribunais, 2014.

OLIVA, M. D.; RENTERÍA, P. Tutela do consumidor na perspectiva civil-constitucional: A cláusula geral de boa-fé objetiva nas situações jurídicas obrigacionais e reais e os Enunciados 302 e 308 da súmula da jurisprudência. Revista de Direito do Consumidor, São Paulo, v. 101, p. 103-136, set./out., 2015. 
OST, F. O tempo do direito. Tradução de Élcio Fernandes. Bauru: Edusc, 2005.

PEDRA, A. S. A. As mutações constitucionais e o limite imposto pelo texto da Constituição: uma análise da experiência latino-americana. Revista Brasileira de Estudos Políticos, Belo Horizonte, n. 101, p. 7-36, jul.-dez. 2010.

PERERA, A. C. El derecho civil: señas, imágenes y paradojas. Madrid: Tecnos, 1988.

PERLINGIERI, P. Perfis do direito civil: introdução do direito civil constitucional. Tradução de Maria Cristina de Cicco. 2. ed. Rio de Janeiro: Renovar, 2002.

PIANOVSKI, C. E. R. A importância de uma teoria (geral) do direito civil. In: TEIXEIRA, A C. B.; LEITE, G. P. L. (Coord.). Manual de Teoria Geral do Direito Civil. Belo Horizonte: Del Rey, 2013. p. 143- 162.

PIANOVSKI, C. E. R. Teoria crítica de Luiz Edson Fachin e a superação do positivismo Jurídico (Prefácio). In: FACHIN, L. E. Teoria crítica do direito civil. 3. ed. São Paulo: Renovar, 2012. p. XVII.

SCHIER, A. da C. R. Serviço público: garantia fundamental e cláusula de proibição de retrocesso social. 2009. 223 f. Tese (Doutorado em Direito do Estado) - Universidade Federal do Paraná, Curitiba, 2009.

SCHREIBER, A. Direito civil e constituição. São Paulo: Atlas, 2013.

SCHREIBER, A.; NEVARES, A. L. M. Do sujeito à pessoa: uma análise da incapacidade civil. In: TEPEDINO, G. et al. $O$ direito civil entre o sujeito e a pessoa: estudos em homenagem ao professor Stefano Rodotà. Belo Horizonte: Fórum, 2016. p. 39- 56.

STRECK, L. Uma leitura hermenêutica das características do neoconstitucionalismo. Revista da AJURIS, Porto Alegre, v. 40, n. 132, p. 185-208, 2013.

SUNDFELD, C. A. Que Constituição? In: SUNDFELD, C. A. Direito administrativo para céticos. São Paulo: Malheiros, 2012. p. 341- 350.

TEPEDINO, G. Crise das fontes normativas e técnica legislativa na parte geral do Código Civil de 2002. In: TEPEDINO, G. (Coord.). O Código Civil na perspectiva civil-constitucional: parte geral. Rio de Janeiro: Renovar, 2013. p. 1- 18.

TEPEDINO, G. Marchas e contramarchas da constitucionalização do direito civil: a interpretação do Direito Privado à luz da Constituição da República. [Syn]Thesis, Rio de Janeiro, v. 5, n. 1, p. 15-21, 2012.

TEPEDINO, G. O papel atual da doutrina do direito civil entre o sujeito e a pessoa. In: TEPEDINO, G.; TEIXEIRA, A. C. Brochado; ALMEIDA, V. (Coord.). O direito civil entre o sujeito e a pessoa: Estudos em homenagem ao professor Stefano Rodotà. Belo Horizonte: Fórum, 2016. p. 20-22.

TEPEDINO, G. Premissas metodológicas para a constitucionalização do direito civil. In: TEPEDINO, G. Temas de direito civil. Rio de Janeiro: Renovar, 1999. p. 1- 22.

VENTURI, T. G. P. Responsabilidade civil preventiva. São Paulo: Malheiros, 2014.

WIEACKER, F. História do direito privado moderno. Tradução de Antônio Manuel Hespanha. Lisboa: Fundação Calouste Gulbenkian, 1980.

ZANETI JUNIOR, H. Cortes Supremas e intepretação do direito. In: GALLOTTI, I. et al. (Coord.). 0 papel da Jurisprudência no STJ. São Paulo: Revista dos Tribunais, 2014. p. 177- 200.

Recebido em: 02/03/2018

Aprovado em: 22/08/2018 